\title{
Como lidar com os fascismos hoje?
}

\author{
Karl Schurster ${ }^{I}$ \\ Michel Gherman ${ }^{I I}$
}

Resumo: Este artigo tem como objetivo analisar as práticas discursivas e o agir político dos variados tipos de fascismo hoje. Partindo da crise das instituições democráticas e do avanço de políticas da chamada direita radical, procuramos compreender quais as características desse "novo" fascismo e como ele se desenvolve, utilizando para isso o campo teórico clássico e contemporâneo e a metodologia comparativa. Além de um breve histórico sobre o conceito de fascismo no Brasil, enveredamos para a elaboração de um mínimo comum entre esses novos fascismos, comparando-os com o dos anos 20 e 30 do século passado. Sendo assim, problematizar categorias como conspiração, negacionismo, negação da alteridade, guerra permanente e disseminação do ódio são fundamentais para entendimento desse "novo" fenômeno político e histórico.

Palavras-chaves: Fascismos. Direita Radical. Nazismo.

\section{How to deal with fascisms today?}

\begin{abstract}
This article aims to analyze the discursive practices and political action of various types of fascism today. Starting from the crisis of democratic institutions and the advancement of policies of the so-called radical right, we try to understand the characteristics of this "new" fascism and how it develops, using the classical and contemporary theoretical field and comparative methodology. Besides a brief history of the concept of fascism in Brazil, we have embarked on the elaboration of a common minimum among these new fascisms, comparing them with that of the 1920s and 1930s. Thus, problematizing categories such as conspiracy, negation of otherness, permanent war and the spread of hatred are fundamental to understanding this "new" political and historical phenomenon.
\end{abstract}

Keywords: Fascism. Radical Right. Nazism.

Texto recebido em 03/07/2020 e aprovado em 20/07/2020. 


\section{Os Fascismo como ameaça à democracia}

Universidade de Viena, 1967. A convite de um grupo de estudantes, o filósofo Theodor Adorno proferiu a conferência intitulada Aspekte des neuen Rechtsradikalismus ${ }^{\text {III }}$ (Aspectos do novo Radicalismo de Direita). A natureza de sua fala estava direcionada a uma "novidade" no cenário político da República Federal da Alemanha de então, os bons resultados eleitorais alcançados pelo partido Nationaldemokratische Partei Deutschland (NPD), fundado em 1964.

No início do seu pronunciamento, Adorno argumentou que ainda seguiam vivas as condições sociais que determinaram a ascensão e a consolidação do fascismo na Alemanha. $\mathrm{O}$ autor alemão afirma que mesmo que não sejam condições ligadas a política no estrito senso, elas estavam vivas na sociedade. Esta colocação de Adorno acabou por se tornar, mesmo de forma não intencional, um jargão dentro da sociedade civil, da imprensa e grupos políticos.

Inúmeros foram os políticos, intelectuais e jornalistas que afirmaram, após 1945, que o fascismo continuava sendo um perigo real e que o fim do regime nacionalsocialista alemão não significava que o espectro do fascismo teria sucumbido aos escombros da guerra. Segundo essas análises, seria apenas a versão que conseguiu ascender ao poder, controlando o Estado e suas instituições, que teria sido derrotada.

Os fascismos como ideia e como cosmovisão de mundo não morreram em maio de 1945, quando a mando do Almirante Karl Dönitz, o General Alfred Jodl assina, sem condições prévias, a rendição alemã. De fato, ocorre que quando o descrédito nas instituições que compõe o Estado se torna maior do que o reconhecimento de sua autoridade, a recorrência do fascismo passa a ser um dos caminhos possíveis.

O fenômeno do fascismo acaba por preencher e acolhe brechas deixadas por um vácuo político nas sociedades democráticas. Portanto, os fascismos não devem ser tratados como um fenômeno morto ou exclusivamente pertencente a um passado distante e findado. O fato é que, desde o fim da Segunda Guerra Mundial, em 1945, a sociedade e a política ocidental conviveram com o espectro dos fascismos rondando sua porta.

Setenta e cinco anos depois, os conceitos de "fascismo" e "nazismo" foram usurpados pelo senso comum, se transformando em um adjetivo social que explicaria fenômenos mais comportamentais do que propriamente políticos. Nota-se que o termo "fascismos" ou "fascistas" foi utilizado, de forma indistinta, para classificar grupos considerados de esquerda e direita, religiosos ou seculares, autoritários ou não. Esse uso excessivo acaba por transformar a ideia de fascismo, como já afirmou Raymond Aron, na própria definição do "outro", o inimigo que se quer atingir e desqualificar IV .

Podemos afirmar, em nosso tempo presente, que tanto os partidários do que convencionamos denominar de fascismo histórico, justamente em referência à primeira metade do século XX, como os partidários dos "novos" fascismos encontram-se divididos e distribuídos de forma bastante dispersa ao redor do mundo. 


\section{COMO LIDAR COM OS FASCISMOS HOJE?}

KARL SCHURSTER E MICHEL GHERMAN

Um dos equívocos produzidos por análises menos cuidadosas está justamente em pensar que os fascismos estão presentes única e exclusivamente na esfera política, sendo assim, fenômenos institucionalizados. Por esse pensamento, o sinal de alerta apenas acende quando partidos políticos da direita radical se fortalecem e conquistam resultados eleitorais significativos. Contudo, tomando como base os exemplos históricos conhecidos, os fascismos originam-se como movimento social mais amplo e disseminado, e somente em outras fases, eles se institucionalizam, constituindo, então, partidos políticos propriamente ditos. Somente em momentos mais extremos, tais forças ocupam as estruturas estatais.

\section{Fascismo como fenômeno plural}

É possível notar que acima utilizamos o conceito do fascismo no plural. Há, pois, uma ampla discussão na historiografia alemã e especializada que aborda os fenômenos fascistas utilizando o conceito dessa forma. Um estudo pioneiro, nesse sentido, data de 1963 e foi publicado pelo controverso historiador alemão Ernst Nolte ${ }^{\mathrm{V}}$, Der Faschismus in seiner Epoche (O fascismo em sua época), onde analisou, de forma comparativa, os casos francês, italiano e alemão.

No Brasil, esse debate data dos anos 1970 e teve como principal articulador o professor Francisco Falcon ${ }^{\mathrm{VI}}$. Seu texto, Origens históricas dos movimentos fascistas (na mesma coletânea em que, O fascismo como fenômeno metapolítico, do prof Ernst Nolte ${ }^{\mathrm{VII}}$ foi publicado), foi um dos primeiros a analisar do ponto de vista teórico o porquê do uso do plural para explicar aqueles movimentos e fenômenos históricos. A priori, a discussão sempre girou em torno do pensamento do historiador italiano Renzo de Felice ${ }^{\mathrm{VIII}}$. Foi dele a tese de separação entre a ideia de fascismo como Estado e fascismo como movimento, dando ao termo um caráter polissêmico, de vários significados.

Em 1991, Francisco Falcon retorna a essa discussão em seminário na UFRJ sobre os autoritarismos, organizado por José Luiz Werneck da Silva ${ }^{\mathrm{IX}}$. O encontro tratou da questão do uso dos "fascismos" como uma querela, uma polêmica disputa entre os historiadores. Para Falcon, esse conceito nos colocava diante de mais um dos famosos "ismos" da política contemporânea.

$\mathrm{Na}$ ocasião, Falcon defendeu o caráter polissêmico da origem do termo. $\mathrm{O}$ historiador afirmou que tivemos o "fascismo" e os "fascismos". O primeiro deles estava vinculado aos próprios agentes históricos, aos movimentos e partidos de época. Enquanto o outro, os "fascismos" (esse no plural), pertencente aos historiadores que chamou de tendência nominalista, que repugnariam o uso dos conceitos. $\mathrm{O}$ fascismo, seja ele ou não historicizado, foi típico dos historiadores teorizantes, dos intelectuais de tendência 'realista'. Sua observação, de forma geral, mostrou que mesmo com muitas diferenças, a depender de que caminho teórico for escolhido, o "fascismo" como conceito científico seria algo realmente existente.

É bastante singular lembrar que os textos do Francisco Falcon ${ }^{\mathrm{X}}$ e do Leandro Konder $^{\mathrm{XI}}$ atualizaram a discussão no Brasil sobre os fascismos de forma pioneira. Contudo, mesmo reconhecendo o equívoco da generalização, o uso indiscriminado do fascismo, no singular, acabou sendo contraditório. Sua utilização procurou unificar o 


\section{COMO LIDAR COM OS FASCISMOS HOJE?}

KARL SCHURSTER E MICHEL GHERMAN

que foi e continua sendo plural. Essa visão partia para um campo conceitual e abstrato se perdendo, em muitos momentos, na teoria ou mesmo filosofia política. Houve, por essa geração, uma grande dificuldade em entender as várias dinâmicas dos regimes fascistas apresentando uma distinção latente entre o que seria a teoria explicativa e o fenômeno histórico em $\mathrm{si}^{\mathrm{XII}}$.

Seguido a esses debates, a reflexão realizada por Francisco Carlos Teixeira da Silva, em Os Fascismos, avançou tanto do ponto de vista teórico, quanto dos fascismos como processos históricos. Para ele, denominamos de fascismos "o conjunto de movimentos e regimes de extrema direita que dominou um grande número de países europeus desde o inicio dos anos 20 até 1945"XIII. Por conseguinte, todas as expressões derivadas da realidade política da ascensão das direitas radicais nesse período, quer se chamasse franquismo, salazarismo, hitlerismo, nazismo, nacional-socialismo, poderiam ser intitulados como fascismo. O termo, derivado do latim e de uso político na Itália dos anos 1920, se deu pelo fato do regime de Mussolini ter servido como um modelo e por ter sido o primeiro a ascender ao poder como governo e não pela originalidade em si do processo histórico.

Assim, defendemos que entender os fascismos, no plural, é uma proposta fundamental na quebra de uma visão que circunscreveu o fenômeno à Itália e à Alemanha. Em vários momentos, se confundia com a própria história da Alemanha como se fosse uma continuidade, um caminho especial ou mesmo uma maldição da nação. As suas reflexões, apontaram para a necessidade de garantir a universalidade dos fascismos como fenômenos históricos e, além disso, a importância de garantir uma autonomia para a construção de uma teoria em relação aos seus aspectos constitutivos. XIV

Retirar a ideia de exclusividade italiana e alemã é fundamental para podermos entender como os fascismos se originaram, chegaram ao poder e persistem como uma ameaça constante e real, mesmo no século XXI. Lutz Winckler ${ }^{\mathrm{XV}}$ estava correto quando afirmou que sem uma teoria política do fascismo seria inconcebível, ou quase mesmo impossível, uma crítica a linguagem desse movimento.

Nossa preocupação não está necessariamente em como lidar com os fascismos de forma institucional - eleitoral, mas sim de como enfrentar de forma sistemática a identificação de grupos e indivíduos que, dentro ou não da esfera política institucional, reproduzem o agir político dos fascismos. Concordamos, portanto, com Adorno ao afirmar que os "movimentos fascistas são os estigmas, as cicatrizes de uma democracia que até o momento não conseguiu entender devidamente todo seu verdadeiro sentido".

\section{As formas dos fascismos hoje}

$\mathrm{Na}$ atual conjuntura, tem se tornado cada vez mais clara a concepção de que os fascismos históricos como oposição às democracias, guardadas suas devidas proporções dos regimes de Estado, foi menos nefasto a democracia, do que a emergência dos "novos fascismos". O agir democrático e a democracia como forma de governo são legados fundamentais do combate aos fascismos históricos. A degeneração da democracia, perpetrada pelo agir político fascista, seja no Brasil (Bolsonaro), Hungria (Órban), Tanzânia (Mugufuli) ou mesmo nos movimentos em outros países que se 


\section{COMO LIDAR COM OS FASCISMOS HOJE?}

KARL SCHURSTER E MICHEL GHERMAN

utilizam do fascismo e colocam a sociedade em risco, constroem o medo como razão de alcance emocional e tem, como único fim, a tomada do poder, sem apresentar nenhuma proposta a nação, nem ideológica, tampouco de futuro. $\mathrm{O}$ alimento da política e do discurso fascista é a eterna sensação de que o país vai de mal a pior e que apenas eles, os fascistas, seriam capazes de restituir o que a sociedade perdeu, seja por defender um ultra fanatismo em costumes, retomando pautas já superadas, ou com o discurso de que são a própria renovação de uma política carcomida pela corrupção.

Em nosso tempo presente os fascismos estão dentro da própria democracia, utilizando suas regras e regulamentos para subverter a possibilidade da construção de retomar um projeto comum para a sociedade. Hoje, a institucionalização dos fascismos não está em oposição a regimes democráticos, mas em uma destruição gradual do agir, do ambiente democrático e das próprias instituições democráticas. O modo de atuar no novo-fascismo promove uma erosão do ambiente democrático. A Erosão é gradual, cria inimigos internos, produz isolamento, enfim, ameaça o sistema como um todo. Esse novo-fascismo retoma aquilo que foi identificado por Madeleine Albright ${ }^{\mathrm{XVI}}$ como a forma mais extrema de regime autoritário, contudo dentro de um verniz democrático. A linguagem e prática desses fascismos abrem fissuras nas estruturas políticas e sociais que um século pode não ser tempo suficiente para recompor. Sua principal estratégia é a "massificação da brutalidade"XVII , transformando a política num exercício de linguagem da violência e de extensão de práticas do ódio. Por mais que o contexto seja outro a campanha segue a mesma perpetrada por Mussolini, "Drenar la Palude" (Drenar o Pântano). Por isso, lidar com os fascismos nos obriga a não poder renunciar uma crítica rigorosa a linguagem, sob pena dessa renúncia colocar em risco a própria sociedade.

Reafirmamos que o nacional-socialismo foi uma manifestação histórica do fascismo e que não há como ele se manifestar no presente da mesma forma. A linguagem e o agir fascista não se encontram mais dentro apenas das condições históricas do passado, mas estão presentes nas estruturas da sociedade estimulando os instintos destruidores de seus adeptos. Ao atribuir o eterno mal-estar, a hiância, ao sistema político e econômico e a seus representantes reconstrói estereótipos, clichês de uma verborragia autoritária com um intuito exclusivamente dominador.

Nesse sentido, podemos dizer que o que nos salvou dos fascismos históricos, a democracia, está, hoje, em grande risco. A possibilidade de falência da democracia como uma prática universal que caiu em profundo descrédito perante a sociedade está presente. $\mathrm{O}$ perigo reside em permitir que o funcionamento das instituições democráticas esteja a serviço de uma concepção de nação "forjada" por meio da construção de sucessivos "outros convenientes".

Seguindo os estudos de Theodor Adorno sobre a personalidade autoritária ${ }^{\text {XVIII }}$, os fascismos insistem de forma rígida em normas ditas morais e submetem a sociedade ao critério e visão de mundo do "in-group" dominante, forçando seus adeptos a uma rejeição estereotipada e com métodos de "aniquilação" do "out-group" fíctício (sejam eles judeus, como no exemplo histórico, ou gays, negros, adeptos de religiões afro), construindo para isso mirabolantes teorias conspiratórias e fantasias das mais absurdas.

Como um exemplo dessa prática, há a atitude do atual Ministro das Relações Exteriores do Brasil ao dizer que a pandemia do novo Coronavírus é uma tentativa de 


\section{COMO LIDAR COM OS FASCISMOS HOJE?}

KARL SCHURSTER E MICHEL GHERMAN

implementar o "comunavírus"XIX . O fato é que essa mensagem, quando dirigida ao que Adorno chamou de "indivíduo potencialmente fascista", aquele que está vulnerável a linguagem autoritária, é capaz de transformar elementos do campo da linguagem em ação efetiva. E o absurdo passa a ser concreto, plausível e possível. Por mais que a maioria dos indivíduos não seja capaz de fazer da ideia uma ação aberta, outros que levam essa linguagem autoritária como um discurso de fé farão dessas opiniões, atitudes e valores. Com isso tais elementos serão construtores de inimigos imaginários e de uma ampla violência social.

\section{O mínimo fascista}

A complexa conjuntura, da crise econômica de 2008 até o presente momento (2020), indica que os "novos" fenômenos fascistas são múltiplos e não possuem, muitas vezes, uma ligação muito clara. É, por excelência, mais plausível a construção de uma aproximação entre os diversos fascismos históricos, elaborando um mínimo fascista (conceito que explicitaremos adiante), do que tentar construir uma conexão entre os variados movimentos sociais e políticos que existem hoje. Não há, portanto, elo entre o Front National, na França, e o Aurora Dourada, na Grécia, assim como não é possível uma comparação precisa entre governos de direita radicais como o do presidente do Brasil, Jair Bolsonaro, e Viktor Órban, na Hungria.

Comparar os movimentos políticos e sociais do "novo" fascismo é um procedimento fundamental para aquilo que Ernst Nolte denominou de mínimo fascista. A construção de uma tipologia, quase que de modo weberiano, nos possibilitará a construção de um "modelo de fascismo" onde será possível levar em consideração as diversas experiências contemporâneas de fascismo, mesmo que não tenham obtido êxito na tomada do poder. Não podemos cair na armadilha de considerar apenas aqueles fascismos que conseguiram alçar ao status de governo. Muitos movimentos, como o Jobbik na Hungria ou o Pegida na Alemanha são exemplos claros de fascismo contemporâneo. Todas essas experiências políticas fascistizantes devem ser recuperadas e ordenadas para possibilitar um modelo a ser proposto.

Para lidar com os fascismos não podemos igualar os diferentes radicalismos de direita, que em muitos momentos são conjunturais, com estruturas ideológicas capazes de tomar o Estado e remodelar todas as instituições políticas e sociais. Partidos como o Nationaldemokratische Partei Deutschland (NPD) na RDA ou o Alternative für Deutschland (AfD), 2013, tiveram e têm, respectivamente, uma popularidade ou adesão controlada, mostrando que em toda sociedade, em variados tempos e espaços, os fascismos sempre encontram uma linguagem política capaz de se fazer presente na vida pública.

Os fascismos nos impõem a necessidade de preparação da sociedade para o enfrentamento de uma grande crise, seja ela política, econômica, ou mesmo de saúde, como epidemias e pandemias. Nos fascismos históricos foi fundamental o controle não só da crise, mas, acima de tudo, do imaginário social. Há um fator sociopsicológico, como afirmou o psicanalista Wilhelm $\operatorname{Reich}^{\mathrm{XX}}$, que demonstra que os fascismos históricos 'desejavam' a catástrofe e faziam dela suas fantasias mais reais. $\mathrm{O}$ apelo ao desejo, quase que inconsciente, de uma catástrofe é uma das bases estruturais de uma política fascista. Sendo assim, se o meu inimigo construído ou inventado conseguir o 


\section{COMO LIDAR COM OS FASCISMOS HOJE?}

KARL SCHURSTER E MICHEL GHERMAN

poder ou acessar as estruturas de Estado trará o caos e a destruição. Esse argumento tem sido repetidamente utilizado pela chamada "nova direita radical", ao menos no Brasil, para tentar se fortalecer. Assim, surgem no imaginário ameaças de um novo comunismo, ou dos homossexuais, de esquerdistas, ou mesmo as feministas, ou quaisquer outros grupos que aparecem como responsáveis por essa iminente destruição, mesmo que essa construção discursiva e imagética não seja capaz de definir sequer quem esses grupos são exatamente.

Os atuais governos ou movimentos políticos que são denominados fascistas, ou que possuem um agir político fascista, são identificados pela dificuldade de apresentar ideias de forma organizada de compreensão da sociedade e da própria realidade. Sobre esse aspecto, devemos levar em consideração o perigo de subestimar esses governos e movimentos pelo seu baixo nível intelectual, pela sua aparente ou até mesmo real falta de ideologia. É, em verdade, uma ausência de visão política pensar que seu êxito está diretamente atrelado a força de uma "ideologia".

A característica mais marcante nos novos fenômenos fascistas está na apropriação das diferentes linguagens de comunicação e no uso de expressões e termos que são facilmente apropriados pelo seu público alvo. Eles não possuem o desejo de se apresentarem como universalistas. Seu público é facilmente identificado e quantificado. São aqueles indivíduos, em grande maioria, capazes de transformar a política, parafraseando o historiador George Mosse ${ }^{\mathrm{XXI}}$, em religião cívica. Então, o uso massivo de todos os atuais meios de linguagem comunicativa, em especial as redes sociais, são o centro de gravidade do novo discurso e agir político dos fascismos.

As origens da ressurgência de políticas fascistizantes não estão, necessariamente, atreladas a estruturas socioeconômicas há muito estabelecidas, por exemplo no caso brasileiro. Vivemos momentos de profunda desestabilização política e social a partir das massivas manifestações sociais ocorridas entre 2013 e 2014, as chamadas jornadas de junho, isso, perpetuou-se durante o processo de impedimento jurídico da ex-presidente Dilma Rousseff e culminou na eleição de Jair Bolsonaro. A crise nos governos de centro-esquerda no Cone Sul possibilitou o (re)surgimento de práticas discursivas e sociais próprias de uma ação política fascista.

\section{Negacionismo no subfascismo (unterfascismus)}

Uma característica marcante, disso que aqui vamos chamar de unterfascismus (subfascismo), é o negacionismo XXII como prática, a dispersão da sociedade civil organizada e a pulverização da oposição, tomando para si as pautas políticas, quaisquer que sejam elas. Há, e aqui concordamos com Richard Bessel, algo em comum com essa prática fascistizante atual e o fascismo histórico: ambos existem em um estado permanente de guerra.

Se no passado ela foi racial, com um forte e avassalador antissemitismo, um ódio racial aos judeus, hoje ela é diariamente discursiva sobre a interpretação da realidade e da revisão sistemática do passado. Há um claro projeto em permanente atuação de passar o passado a limpo. Mais do que uma guerra racial, tal qual ocorreu no passado recente, o atual agir político fascista encampa uma disputa de narrativas, buscando substituir as lembranças sobre os eventos e processos históricos passados por um "mito" 


\section{COMO LIDAR COM OS FASCISMOS HOJE?}

KARL SCHURSTER E MICHEL GHERMAN

da experiência desses processos. George Mosse nos alertou que a construção desse tipo de "mito", projetado para a sociedade, tem a intenção de mascarar e legitimar algum tipo de "realidade intencional", funcionando como um substituto da realidade.

Um exemplo de destaque nessa questão tem sido John Magufuli, presidente da Tanzânia. Sendo um outsider da política do seu país, esse professor de matemática, com doutorado em química, se elegeu sob o lema: "trabalho, trabalho e trabalho". Levantou a bandeira anticorrupção, sendo chamado pelos seus correligionários de incorruptível e até pelo apelido de "tingatinga", "trator" em suaíli, iniciando no país um considerado número de obras de infraestrutura. Com um agir político caricatural, tipicamente fascista, transformou o dia da independência do país no dia da "limpeza nacional". Divulgou pelas mídias digitais uma foto limpando o palácio presidencial, pegando o lixo com as próprias mãos. Entretanto, esse arrojo de políticas e ações populares não foram suficientes para esconder todo viés autoritário, antidemocrático de sua gestão. Jornais e emissoras de televisão que atestaram oposição a seu governo foram fechados e diversos políticos foram presos sob a alegação de incitação ao ódio, além do desaparecimento de um jornalista que investigava uma série de assassinatos no país.

Sua batalha mais recente tem sido contra a ideia de que a pandemia do novo coronavírus que assola o mundo (2020) nada mais é do que uma "sabotagem imperialista". Proibiu a divulgação de dados diários sobre a propagação da doença, alegando que isso espalharia apenas o medo entre a população. Além disso, foi a público solicitando que a população rezasse para combater o vírus, defendendo que a doença não seria capaz de sobrevier no "corpo de Cristo". Enviou amostras de animais e de mamões para o laboratório responsável pela análise do vírus, com a justificativa de que se um mamão pegou o vírus sem cumprir o distanciamento físico, estaria com isso provado o quanto a política de isolamento seria sem sentido. ${ }^{\text {XIII }}$ Aconselhou a população a não se preocupar com essa "gripe", novamente reafirmando teorias conspiracionistas de que "alguém estaria fazendo um jogo sujo", expressão muito utilizada nos fascismos históricos.

Há algo bastante singular nisso que Walter Benjamin identificou nos fascismos como "estetização da política"XXIV. A construção de um mundo mítico, quase que paralelo a realidade, com conversões radicais de valores tem, nos fascismos, uma correlação linguística que provoca uma destruição da sintaxe e do que podemos chamar de conteúdo significativo, aquilo que seria socialmente comunicável. Um exemplo claro disso está no discurso político do governo Donald Trump. Além de ter negado radicalmente o perigo e efeitos da pandemida de Covid-19, tal como Jair Bolsonaro e John Magufuli, disseminando informações de que o vírus teria sido criado em laboratório pela China, Trump tem defendido de forma sistemática o fim do isolamento social, até o momento a medida mais eficaz contra a propagação do vírus, afirmando publicamente que a manutenção da política de isolamento nada mais é do que uma ação do Partido Democrata para "prejudicá-lo politicamente"XXV nas eleições de 2020.

A linguagem fascista persiste na criação de inimigos eternos e promove um combate permanente. Constrói um antimundo inimigo, não com promessas de um futuro promissor, mas, acima de tudo com proibições. Alimenta-se de renúncia e destruição. A linguagem fascista é direta e objetiva, como a fala de Trump ao relatar todos os que perderam o emprego pela pandemia. É capaz de indicar imediatamente o que quer, entretanto, com uma inversão radical de valores, até mesmo do valor a vida. 


\section{Os fascismos no tempo presente}

Para enfrentar os fascismos, é fundamental compreender como a nossa sociedade construiu uma "tolerância social" das práticas fascistizantes e como esse mecanismo se normalizou dentro do nosso tecido social e político. Segundo o Ibope, os eleitores de Jair Bolsonaro, candidato que assumiu práticas típicas da direita radical no pleito de 2018, atualmente sem partido, foram majoritariamente masculinos de jovens de 16 a 24 anos. Ou seja, a geração que começa a aderir, em grande parte, a práticas autoritárias e fascistizantes não vivenciou esse passado e foi muito pouco tocada pela sua realidade e consequência.

No exemplo histórico, parte da geração que aderiu ao nazismo dos anos 1930 foi de nascidos entre 1900 e 1910. Eles não vivenciaram a dura experiência da Primeira Guerra no front de batalha e só a sentiram já no processo de reelaboração do passado onde o mito da traição ou da punhalada pelas costas, já estava solidificado na sociedade civil alemã.

A narrativa sobre a qual milhões de pessoas depositam sua fé, de forma transcendental, em um novo líder messiânico, capaz de resolver toda a crise econômica e política, seja em escala nacional ou mesmo no global player, é uma fé na permanência de que a batalha de narrativas não se esgotará. A meta de combater inimigos imaginários continua, com outros inimigos, em outro formato.

As novas personalidades políticas que estão correlacionadas por parte da sociedade, dos intelectuais e dos meios de comunicação com agir fascistizante, como Trump, Bolsonaro, Órban, Erdogan, dentre outros, devem ser explicados com base nas histórias nacionais de cada um desses países.

Contudo, o que temos visto é uma retirada da explicação histórica desses governos para uma tentativa de entendimento pelo "acidente político", como se esses governos fossem um caminho especial, único e talvez não mais possível de ser reproduzido. É exatamente essa análise que os constrói como "mitos". É neste sentido que se elabora socialmente o chamado "mito do líder", como já bem estudou o historiador Ian Kershaw ${ }^{X X V I}$. Uma ação fundamental no combate aos fascismos de hoje é a desconstrução dessa "fabricação" mitológica de líderes que representam setores específicos da sociedade e são capazes de fazer seu discurso ser direcionado a cada um dos seus ouvintes, contemplando seus seguidores. Nossa função é desativar esse dispositivo social mostrando as contradições, as discrepâncias e as incoerências desses discursos radicais, muitas vezes xenófobos e excludentes.

Lile, ou Alice Weidel, uma das lideranças da AfD (Alternativa para Alemanha), partido da direita radical alemã, é assumidamente lésbica, com carreira em bancos de investimento e defende abertamente políticas anti-imigratórias e antigay. Casada com uma produtora de cinema e com duas filhas, ela se define como parte de uma "família moderna". Quando o parlamento alemão legalizou a união homoafetiva em 2017, ela declarou que com profunda tristeza se despediam "da família alemã, cuja proteção foi enterrada pelos "representantes do povo". XXVII A exposição das contradições dentro dos 


\section{COMO LIDAR COM OS FASCISMOS HOJE?}

KARL SCHURSTER E MICHEL GHERMAN

discursos fascistizantes é um artefato fundamental no combate à disseminação do ódio e da negação da alteridade presente no discurso radical. Tal aspecto transforma-se numa questão ética e moral. O uso da história como advertência aos potenciais seguidores desse radicalismo fascistizante, mostrando quais as consequências sociais causadas por esse discurso e prática política, torna-se um dever.

A linguagem fascista apresenta a vantagem, para parte da população, de servir de barreira contra o suposto "medo comunista", que no cenário contemporâneo está ligado a qualquer tipo de oposição ao recente status quo. Todas as manifestações do radicalismo estão marcadas por um conflito permanente entre a impossibilidade de poder dizer algo, já que seu conteúdo é meramente retórico, e a necessidade de fazer seu público cativo entrar em ebulição, transformando o discurso em ato político.

Alguns teóricos que se debruçaram nos estudos sobre os fascismos, dentre eles os frankfurtinianos, como Adorno e Marcuse, foram diretos ao apontar que esses movimentos nunca tiveram uma teoria realmente elaborada, a ponto de podermos chamar de ideologia. Sua lógica estava mais direcionada para a tomada do poder e possuía uma perspectiva de exercício do domínio absoluto e coercitivo. Para o fascismo histórico, aspectos ideológicos estavam em segundo plano. Para os discursos fascistas atuais não parece diferente. Há uma Gestalt que utiliza o predomínio da propaganda em novos meios de linguagem e bombardeiam os indivíduos com conteúdos simplórios, repetitivos e estereotipados, exatamente por ser incapaz de apresentar um conceito ou um conteúdo concreto. O discurso fascista apela para a linguagem do absurdo. Distorce aquilo que no passado foi utilizado para realizar uma alegoria sobre o presente confuso e opaco.

Enquanto o teatro do absurdo, de Eugène Ionesco ${ }^{\mathrm{XVVIII}}$, estava repleto de metáforas sobre conformismo, frieza e agressividade, se referindo para isso na transformação de seres humanos em "rinocerontes", o atual discurso fascista é capaz de defender a tese de que a terra é plana, ou mesmo de que uma pandemia como a do Covid-19, nada mais é do que uma conspiração internacional. O 'absurdo' retorna não como metáfora de representação de um mundo a ser compreendido, problematizado, mas como invenção de uma razão que busca o monopólio do discurso para fazer da realidade a sua própria representação. Um exemplo disso no fascismo histórico foi a descabida narrativa construída pelo nazismo de que os rabinos defendiam a britmilá $^{X X I X}$, que na linguagem nazi foi traduzida de forma pejorativa por castração de todos os alemães. Essa técnica de tornar pública as mais fantasiosas e absurdas mentiras são utilizadas como ferramenta política no fascismo contemporâneo e demandam um grande esforço por parte dos antifascistas em demonstrar que todas essas construções não passam de falácias, embora sejam capazes de arregimentar muitos adeptos.

Sendo assim, outra tarefa que nos cabe de forma imperiosa é evitar o que podemos chamar de "confissão de culpa". Nenhum regime fascista ou mesmo com ações políticas fascistizantes foram ou são regimes 'bons' que ao longo do tempo se modificaram de forma radical para a imposição de um Estado de exceção, transformando-se em um regime descontrolado por mecanismos institucionais. Todo movimento fascista que consegue alcançar o poder, ou que utiliza das práticas fascistas dentro de um regime democrático, apresenta, muito antes de se tornar governo, as características fundamentais do discurso autoritário, restritivo e impositivo. Isso 


\section{COMO LIDAR COM OS FASCISMOS HOJE?}

KARL SCHURSTER E MICHEL GHERMAN

demonstra que a luta política com o uso adequado de mecanismos de linguagem contemporâneas são fundamentais no combate ao agir fascista.

Michele Murgia ${ }^{\mathrm{XXX}}$ afirmou que os ideais da direita radical apontam para a democracia como um regime instável, insustentável e fraco. Essa fragilidade não desencadeia uma ruptura institucional radical, mas uma transição gradual. Aos poucos as instituições fundamentais vão sendo esvaziadas, perdendo sua autoridade legitimada, de forma que até os democratas tenham a sensação de que a democracia custa caro demais. Por isso, aprender formas e mecanismos de combate ao fascismo são fundamentais para a elaboração de um novo projeto de sociedade.

\section{Notas}

${ }^{\text {I }}$ Livre Docente em História Contemporânea da Universidade de Pernambuco. Pós-doutor em História pela Universidade de Berlim e professor dos Programas de Pós Graduação em História e Educação da UPE. Coordenador do Laboratório de Estudos Israel-Palestina, núcleo UPE.

II Co-Coordenador do Núcleo de Estudos Judaicos da UFRJ, pesquisador do Centro de Estudos de Israel e Sionismo da Universidade Bem Gurion e professor substituto do Departamento de História da UFF. Pesquisador do Instituto Brasil Israel - IBI.

III ADORNO, Theodor. Aspekte des neuen Rechtsradikalismus: Ein Vortrag. Berlin: Verlag, 2019.

IV ARON, Raymond. Democracy and Totalitarism: a theory of political systems. EUA: Michigan Press, 1990.

V NOLTE, Ernst. Der Faschismus in seiner Epoche. Berlin: Piper, 1963.

${ }^{V I}$ FALCON, F. J. C. Origens históricas dos movimentos fascistas. In: RODRIGUES, A. E. M. (Org) Fascismo. Rio de Janeiro: Eldorado, 1974, p. 17-36.

VII NOLTE, Ernst. O fascismo como fenômeno metapolítico. In: RODRIGUES, A. E. M. (Org) Fascismo. Rio de Janeiro: Eldorado, 1974.

VIII DE FELICE, Renzo. Explicar o Fascismo. Lisboa: Edições 70, 1976.

IX DA SILVA, José Luiz Werneck da Silva (Org). O feixe e o prisma. Uma revisão do Estado Novo. Rio de Janeiro: Jorge Zahar, 1991.

${ }^{\mathrm{X}}$ FALCON, F. J. C. Fascismo: Autoritarismo e Totalitarismo. In: DA SILVA, José Luiz Werneck da Silva (Org). O feixe e o prisma. Uma revisão do Estado Novo. Rio de Janeiro: Jorge Zahar, 1991, p. 2943.

XI KONDER, Leandro. Introdução ao fascismo. Rio de Janeiro: Graal, Biblioteca de Ciências Sociais, 1991.

${ }^{\mathrm{XII}}$ Nota-se que nesses debates, a Europa Central e Oriental foram praticamente ignoradas em abordagens sobre o tema. Estas quase que focadas no estudo das experiências fascistas ocorridas em Portugal e na Espanha. Ainda assim, a dinâmica de um regime, como o espanhol de Francisco Franco, fascista até a derrota da Alemanha e que acaba por evoluir até o que poderia chamar de tardofranquismo, se tornando uma ditadura, ou mesmo o criptofascismo de Salazar, de aspecto conservador católico, não foi problematizada como processo histórico no texto de autores que buscaram a todo momento fazer da teoria o primado da explicação dos fascismos.

XIII DA SILVA, Francisco Carlos Teixeira. Fascismos. In: FIHO, Daniel Aarão Reis; FERREIRA, Jorge; ZENHA, Celeste (Org). O século XX. O tempo das crises. Revoluções, Fascismos e guerras. Rio de Janeiro: Civilização Brasileira, 2000, p. 112.

XIV Idem, p. 118 .

${ }^{\mathrm{XV}}$ WINCKLER, Lutz. A função social da linguagem fascista. Lisboa: Estampa, 1978, p. 15.

XVI ALBRIGHT, Madeleine. Fascismo. Um alerta. São Paulo: Crítica, 2018.

XVII HORKHEIMER, Max. Egoismus und Freieheitsbewegung. Disponível em: https://www.gleichsatz.de/b-u-t/kriton/hork/heimerlegofrei.html.

XVIII ADORDO, Theodor. Gesammelte Schriften 9-1. Soziologische Schriften II. Frankfurt am Main: Verlag, 1975.

XIX Disponível em: https://www.cartacapital.com.br/politica/ernesto-araujo-diz-que-pandemia-e-usadapara-implementar-o-comunavirus/. 
XX REICH, W. Psicologia das massas do fascismo. São Paulo: Martins Fontes, 2019.

${ }_{\mathrm{XXI}}$ MOSSE, George. Les racines intellectuelles du Troisième Reich: La crise de l'idéologie allemande. Paris: Calmann-Lévy, 2006.

XXII Segundo Luis Edmundo Moraes, o termo negacionismo, do ponto de vista histórico, "refere-se especificamente a um campo propriamente intelectual de movimentos de extrema-direita do pós-guerra, cujo projeto incorpora principalmente a defesa e a reabilitação do nacional socialismo e do III Reich e a negação da existência dos campos de extermínio e do Holocausto nazista". MORAES, Luis Edmundo. $O$ Partido Nazista no Brasil. Disponível em: http://blog.editoracontexto.com.br/o-partido-nazista-no-brasilentrevista-com-luis-edmundo-moraes/. Acessado em 15.05.2020. Aqui utilizaremos a apropriação do "negacionismo" pelos fascismos contemporâneos. Além de uma revisão sistemática de eventos históricos, como ditaduras, genocídios, há uma característica especial que é a negação do próprio presente. Um exemplo fundamental é a relação entre negacionismo e conspiração, retratada em nosso texto.

XXIII Disponível em: https://brasil.elpais.com/internacional/2020-05-11/john-magufuli-o-bolsonaroafricano.html .

XXIV BENJAMIN, Walter. Das Kunstwerk Im Zeitalter Seiner Technischen Reproduzierbarkeit. Berlin: Reclan, 2011, p. 174.

XXV Disponível em: https://brasil.elpais.com/internacional/2020-05-12/trump-acusa-governadoresdemocratas-de-atrasarem-reabertura-para-prejudica-lo-politicamente.html .

XXVI KERSHAW, Ian. El mito de Hitler. Madrid: Critica, 2012.

XXVII Disponível em: https://www1.folha.uol.com.br/mundo/2017/10/1923308-lesbica-nova-lidernacionalista-alema-e-contra-euro-e-casamento-gay.shtml .

XXVIII IONESCO, Eugène. O Rinoceronte. São Paulo: Nova Fronteira, 2015.

XXIX Circuncisão masculina, consiste na retirada ritual do prepúcio ao oitavo dia de vida da criança.

XXX MURGIA, Michele. Instruções para se tornar um fascista. Belo Horizonte: Ayine, 2019.

\section{Referências Bibliográficas}

ADORDO, Theodor. Gesammelte Schriften 9-1. Soziologische Schriften II. Frankfurt am Main: Verlag, 1975.

2019.

. Aspekte des neuen Rechtsradikalismus: Ein Vortrag. Berlin: Verlag,

ALBRIGHT, Madeleine. Fascismo. Um alerta. São Paulo: Crítica, 2018.

ARON, Raymond. Democracy and Totalitarism: a theory of political systems. EUA: Michigan Press, 1990.

BENJAMIN, Walter. Das Kunstwerk Im Zeitalter Seiner Technischen Reproduzierbarkeit. Berlin: Reclan, 2011.

DA SILVA, Francisco Carlos Teixeira. Fascismos. In: FIHO, Daniel Aarão Reis; FERREIRA, Jorge; ZENHA, Celeste (Org). O século XX. O tempo das crises. Revoluções, Fascismos e guerras. Rio de Janeiro: Civilização Brasileira, 2000.

DA SILVA, José Luiz Werneck (Org). O feixe e o prisma. Uma revisão do Estado Novo. Rio de Janeiro: Jorge Zahar, 1991.

DE FELICE, Renzo. Explicar o Fascismo. Lisboa: Edições 70, 1976.

FALCON, F. J. C. Fascismo: Autoritarismo e Totalitarismo. In: DA SILVA, José Luiz Werneck (Org). O feixe e o prisma. Uma revisão do Estado Novo. Rio de Janeiro: Jorge Zahar, 1991, p. 29-43. 
HORKHEIMER, Max. Egoismus und Freieheitsbewegung. Disponível em: https://www.gleichsatz.de/b-u-t/kriton/hork/heimerlegofrei.html .

IONESCO, Eugène. O Rinoceronte. São Paulo: Nova Fronteira, 2015.

KERSHAW, Ian. El mito de Hitler. Madrid: Critica, 2012.

KONDER, Leandro. Introdução ao fascismo. Rio de Janeiro: Graal, Biblioteca de Ciências Sociais, 1991.

MOSSE, George. Les racines intellectuelles du Troisième Reich: La crise de l'idéologie allemande. Paris: Calmann-Lévy, 2006.

MURGIA, Michele. Instruções para se tornar um fascista. Belo Horizonte: Ayine, 2019.

NOLTE, Ernst. O fascismo como fenômeno metapolítico. In: RODRIGUES, A. E. M. (Org) Fascismo. Rio de Janeiro: Eldorado, 1974.

NOLTE, Ernst. Der Faschismus in seiner Epoche. Berlin: Piper, 1963.

REICH, W. Psicologia das massas do fascismo. São Paulo: Martins Fontes, 2019.

WINCKLER, Lutz. A função social da linguagem fascista. Lisboa: Estampa, 1978.

FALCON, F. J. C. Origens históricas dos movimentos fascistas. In: RODRIGUES, A. E. M. (Org) Fascismo. Rio de Janeiro: Eldorado, 1974, p. 17-36. 